\title{
A inclusão na educação infantil de Vitória: contribui- ções da educação física
}

artigo objetiva compreender as possibilidades de uma prática compartilhada e desenvolver proposições que contribuíssem com os processos de inclusão na Educação Infantil. Os sujeitos são professores que atuam no Centro Municipal de Educação Infantil (CMEI) de Vitória e duas crianças com necessidades educativas especiais (NEE). O referencial teórico-metodológico fundamenta-se na perspectiva histórico cultural (Vygotsky, 2007; Wallon, 2010). A perspectiva de professor reflexivo (Nóvoa, 200I) e as concepções metodológicas dos estudos nos/dos/com os cotidianos orienta a produção desse artigo. As fontes foram os registros fotográficos e filmagens das práticas pedagógicas em 2014 e relatórios avaliativos de dois alunos com NEE. A oferta da educação física no currículo da educação infantil amplia as possibilidades do trabalho colaborativo e potencializam as práticas da educação inclusiva.

Palavras Chaves: Educação Infantil. Educação Física. Inclusão. Mediação.

\section{Inclusion in early childhood education in Vitória: phy- sical education contributions}

The article aims to understand the possibilities of a shared practice and develop proposals that contributed to the processes of inclusion in kindergarten. The subjects are teachers who work in the Municipal Center for Early Childhood Education (CMEI) of Vitória and two children with special educational needs (SEN). The theoretical and methodological framework is based on the historical cultural perspective (Vygotsky, 2007; Wallon, 20I0). The reflective teacher perspective (Nóvoa, 200I) and methodological conceptions of studies in / of / with daily guided the production of this article. The sources were the photographic records and footage of teaching practices in 2014 and evaluative reports of two students with SEN. The offer of physical education in the curriculum of early childhood education expands the possibilities of collaborative work and undermines the practices of inclusive education.

Keywords: Early Childhood Education; Physical Education; Inclusive education; Mediation. 


\title{
Introdução
}

\begin{abstract}
"O sorriso compartilhado é mais que especial; as crianças são nossa motivação em nos entregarmos ao máximo; saborear cada momento com intensidade e alegria. Educação Inclusiva: a alegria de partilhar momentos de vida; sermos incluídos nas vidas desses sujeitos muito especiais. Os profissionais que atuaram e atuam com o compromisso de uma educação inclusiva buscam apenas um sorriso de alegria e a felicidade de bons encontros. Somos movidos pelo desejo de fazer juntos" (Marchiori, 20।4)।
\end{abstract}

É possível reconhecer que a educação mobiliza saberes e práticas, debruça-se sobre o conhecimento sistematizado, as culturas, a vida em sociedade na incumbência da formação humana e acolhida dos novos para o convívio em sociedade. No dizeres de Brandão (2013, p. 9) “[...] não há uma forma única nem um único modelo de educação; a escola não é o único lugar onde ela acontece e talvez nem seja o melhor". Quando especificamos a atuação pedagógica na Educação Infantil, sendo esta a primeira etapa da Educação Básica, faz-se necessário especificar o que é possível coexistir nessa esfera da formação humana e quais conhecimentos são mobilizados para compor a atuação do profissional/professor junto às crianças de zero a cinco anos. Reconhece-se a complexidade que a proposta de desenvolvimento integral para a Educação Infantil interpõe aos sujeitos praticantes desse cotidiano educacional, especialmente, quando se trabalha a partir de uma perspectiva de inclusão e diversidade.

As mudanças de um modelo assistencialista ${ }^{2}$ na Educação Infantil para um modelo educacional foram contundentes e deram nuances de efetivação após a LDB de 1996. Entretanto, o modelo escolar, pautado na divisão dos conteúdos, na seriação do aprendizado, na divisão etária, na fragmentação do conhecimento, na perspectiva cognitiva na qual o silêncio e a imobilização são necessários, na distribuição de disciplinas escolares para professores com formações específicas e por área de conhecimento, com ênfase nas habilidades e competências, individualização do ensino, são como espectros e não atendem às especificidades da Educação Infantil. Referente às questões da inclusão no espaço escolar, é possível reconhecer novas formas e perspectivas da formação humana, na qual a diferença é mais um componente dessa complexa sociedade global. O conceito de "flexibilidade curricular", presente nos documentos oficiais, dialoga diretamente com as Diretrizes

\footnotetext{
I Texto reflexivo apresentado no vídeo "Inclusão CMEI DS 20 I4". A divulgação dos vídeos e imagens estão autorizados para fins pedagógicos. Disponível em: https://www.youtube.com/watch?v=YYqoktNoxYw.

$2 \quad$ Pesquisas realizadas, principalmente, no campo da história da infância e da assistência no Brasil indicam que as políticas sociais dirigidas às crianças durante todo o século XX estiveram pautadas pelo caráter paternalista e assistencial e, quando dirigidas à "criança pobre", revelaram-se e revelam-se repressivas e de caráter policialesco (QUINTEIRO, 2002, p. 149).
} 
Curriculares da Educação Infantil.

A Lei no. 11.274/2006 instituiu o ensino fundamental de nove anos de duração e a inclusão das crianças de 06 anos de idade. As crianças com 06 anos completos até o início do ano letivo não estão mais na educação infantil. A saída da criança de 06 anos da Educação Infantil possibilitou uma revisão nas práticas educacionais em ambos os níveis da educação básica. Tratar as crianças como alunos e, consequentemente, privar suas experiências corporais em detrimento da alfabetização e letramento, impedindo-as de brincar podem indicar uma leitura inadequada para a concepção de crianças que dispomos atualmente. Podemos afirmar, a partir da sociologia da infância (SARMENTO e CERISARA, 2004; CORSARO, 2011; QVORTRUP, 2010 e outros), que as crianças são sujeitos sociais e históricos - estão inseridos socialmente e participam ativamente da vida em sociedade, são produtos e produtores da história - numa relação intergeracional. A experiência que os adultos passaram na infância e os discursos que trazem consigo interferem diretamente na concepção de criança, possibilitando (re)significar as relações de poder, saber e a participação da vida em sociedade.

Veiga (2007, p. 216) argumenta que os estudos da psicologia, aplicados à educação e especificamente ao âmbito escolar, ajudaram a definir, sob critérios científicos, não apenas o "lugar" da criança na infância e a diferença entre crianças e adultos, mas também as diferenças entre as outras fases da vida. A autora deduz que isso permitiu a segmentação da própria infância em diferentes etapas, assim como a designação dos processos de aprendizagem correspondentes a cada fase.

Como perspectiva de trabalho na área da Educação Infantil é possível identificar alguns fundamentos que sustentam a proposta de intervenção do profissional que atua na primeira etapa da educação básica: a linguagem corporal, o movimento, a cultura, a estimulação das habilidades básicas, o acesso ao conhecimento, o cuidado/higiene corporal, a saúde, a oralidade, o letramento, a alfabetização, a musicalidade, a estética, diversidade e inclusão. Ao considerar a integralidade da educação da criança de zero a seis anos, todas essas linguagens e conhecimentos são compartilhados pelos praticantes dessa instituição infantil. Não é possível hierarquizar esses conhecimentos.

Desta forma, o currículo está para além da estimulação das habilidades básicas (correr, saltar, engatinhar, rolar, pendurar, andar, girar, bater, lançar, chutar, etc.)! Está para além das culturas! Está para além das linguagens! O currículo na/da Educação Infantil é um convite à vida, o acesso 
aos signos e símbolos que a humanidade elegeu para se comunicar e perpetuar o conhecimento, é para a criança agora e para a sociedade de amanhã. Neste sentido, uma educação inclusiva rompe com o modelo escolar e desafia seus atores a pensar/refletir e propor um fazer pedagógico que acolha a diversidade e estimule a inclusão das crianças. Cabe perguntar: o currículo Dança? Luta? Brinca? Joga futebol? Pula? Corre? Rola? Canta? Toca? Encanta? Imagina? É prazeroso? É convidativo? Fazendo eco a Debortoli (2008, p. 107): “o que se quer que as crianças aprendam com as experiências culturais?” Independente do estereótipos, das diferenças evidenciadas continuamente, na educação infantil todos são crianças e cada uma é única, é diferente.

“A inclusão é uma mentira!” Esta frase, dita por uma professora da educação especial (AEE) em meados de outubro - já no final do "ano letivo"3 - possibilitou várias reflexões que dialogaram diretamente com a/o presente artigo. O diálogo se estendeu com o intuito de se compreender o contexto. Tratava-se de um desabafo, pois por mais que a professora tentasse "fazer com que a inclusão acontecesse", não percebia o progresso. Havia muitos obstáculos, ora por parte da professora regente, ora por parte da equipe pedagógica, além dos desencontros entre os planejamentos, a família e a rotina do CMEI. Viam-se muitas possibilidades de trabalho com as crianças com NEE, mas estas não ocorriam, pelo menos se mostrava como uma percepção.

Quando se buscou na memória o que se realizou e analisado os relatórios, percebeu-se que poderia ter feito mais, todavia, entre ficar a lamentar as mazelas da educação (e seus condicionantes) e acreditar em uma prática possível, optou-se em entender que as práticas inclusivas na instituição infantil são práticas contextualizadas e sujeitas às diversidades de encontros e desencontros que compõem o fazer pedagógico.

O que move os professores na Educação Infantil? O que move esses sujeitos nas escolhas que fazem à frente de uma área de conhecimento que está inserida no primeiro nível da educação básica? O que faz um professor(a) a viver um tempo aiônico ${ }^{4}$ com os alunos? A cantar cantigas infantis e rir feito criança? A dançar com a alma? A se entregar na confecção de brinquedos? A amarrar cordas e construir pontes? A andar na fita e ser criança de novo? De compartilhar os saberes? A construir "geringonças" para que os cadeirantes participem das aulas? A disputar corridas com

3 A educação infantil, na concepção que acreditamos, deve ser diferenciada da escola regular. Todavia, as nomenclaturas usuais fazem parte desse universo educativo. Ano letivo se refere aos 200 dias que a criança tem direito de frequentar uma instituição infantil, mesmo que entendamos que o tempo com a família, as atividades de lazer e a convivência na comunidade são complementares aos trabalhos desenvolvidos com as crianças de zero a seis anos (completados ao longo do ano).

$4 \quad$ Um dos termos que Walter Kohan (2007) utiliza para falar dos tempos da infância, do devir-criança. Ver: bibliografia. 
um carrinho de mão e a cadeira de rodas? A soltar uma criança na tirolesa e correr ao lado, só para ver um sorriso no rosto de um aluno com deficiências múltiplas? A amarrar tecidos e balançar as crianças da educação especial para estimular sua criatividade? A contar "ginásticas historiadas" e movimentar partes do corpo da criança que ainda não consegue andar? $\mathrm{O}$ que move o professor a planejar ações em conjunto e desejar que as crianças participem das atividades junto com a turma? Quais desejos passam pelo sujeito professor para buscar inovações, diálogos e novas possibilidades de fazer educação inclusiva na educação infantil?

Defendemos que a escola é dinâmica, pulsa com a vida e exige dos profissionais atitudes de reflexão, planejamento e reflexão (práxis). Entendemos que o professor se constitui ao longo do seu processo de formação. Resgata sua história pregressa, apropria-se da formação inicial e constrói sua identidade na atuação em sala de aula. Sendo assim, acreditamos nas práticas possíveis. Isso significa que, dentro das condições oferecidas (da disponibilidade de tempo, material e espaço; das parcerias estabelecidas no cotidiano e das práticas colaborativas), estamos oferecendo o nosso melhor. Ou seja, não é uma visão pessimista e de fracasso, mas uma perspectiva de atuar proativamente com todas as crianças; perceber a individualidade de cada sujeito e suas potencialidades, dado que as impossibilidades ficam estampadas a qualquer um que, de fora, reconhecem apenas as limitações das crianças com NEE.

Seria mentira o que estamos fazendo no CMEI? A inclusão está acontecendo como deveria? O que está faltando para efetivarmos práticas inclusivas? Ou ainda, qual a perspectiva de inclusão que está em evidência nesse cotidiano educacional? Tais questões ecoaram ao longo da produção desse artigo e instiga-nos a pesquisar o que estamos fazendo para oferecer uma escola para todos. Percebemos que a diferença, o diferente, o rótulo que colocamos nas crianças continuam a moldar o fazer pedagógico, a ditar o que pode ou não pode ser feito pelas crianças, com elas.

O presente artigo tem como objetivo geral analisar as práticas pedagógicas que acontecem na Educação Infantil de um CMEI da rede municipal de Vitória/ES que podem propiciar novos olhares que subsidiem a diversidade e a inclusão na primeira etapa da educação básica. Especificamente, busca-se desenvolver proposições que possam contribuir para possíveis rupturas nos processos de inclusão na Educação Infantil pautados em currículos organizados por área de conhecimento, com trabalhos estanques e restritos às salas de Atendimento Educacional Especializado (AEE). 
Os sujeitos da análise correspondem aos professores que atuam com o público alvo da educação especial e duas crianças com necessidades educativas especiais (NEE).

O referencial teórico-metodológico fundamenta-se na perspectiva histórico cultural, com destaque para os estudos de Lev Vygotsky (1896-1934), Mikhail Bakhtin (1895-1975) e Henri Wallon (1879-1962) para compreendermos a relação do sujeito com o outro, a cultura, a linguagem e a afetividade envolvidas na aprendizagem e desenvolvimento humano. A perspectiva de professor reflexivo, "aquele que pesquisa ou que reflete sobre a sua prática, um professor indagador, que assume a sua própria realidade escolar como um objeto de pesquisa, como objeto de reflexão, como objeto de análise” (Nóvoa, 2001) orienta a produção desse artigo, articulado com as concepções metodológicas dos estudos nos/dos/com os cotidianos.

As fontes foram os registros fotográficos e filmagens das práticas nos diferentes ambientes do CMEI no período de fevereiro a outubro de 2014; os relatórios avaliativos dos dois alunos com NEE.

\section{A educação inclusiva na Educação Infantil}

Conforme Victor (2012), desde 2008, convivemos com a atual definição do público alvo da educação especial, estabelecida pela Política Nacional de Educação Especial na Perspectiva da Inclusão - PNEE, que considera os sujeitos da educação especial as pessoas com deficiência, transtornos globais do desenvolvimento e altas habilidades/superdotação:

[...] considera-se pessoa com deficiência aquela que tem impedimentos de longo prazo, de natureza física, mental ou sensorial que, em interação com diversas barreiras, podem ter restringida sua participação plena e efetiva na escola e na sociedade. Os alunos com transtornos globais do desenvolvimento são aqueles que apresentam alterações qualitativas das interações sociais recíprocas e na comunicação, um repertório de interesses e atividades restrito, estereotipado e repetitivo. Incluem-se nesse grupo alunos com autismo, síndromes do espectro do autismo e psicose infantil. Alunos com altas habilidades/superdotação demonstram potencial elevado em qualquer uma das seguintes áreas, isoladas ou combinadas: intelectual, acadêmica, liderança, psicomotricidade e Artes, além de apresentar grande criatividade, envolvimento na aprendizagem e realização de tarefas em áreas de seu interesse (BRASIL, 2008, p. I5).

As práticas educacionais inclusivas, obrigatoriamente, passam pela formação inicial e continuada. Segundo Victor (2012, p. 82):

O interesse em contribuir com o processo de inclusão dessas crianças na Educação Infantil, pela via da formação inicial e continuada de professores, tem sido uma constante em nossas pesquisas, porque vemos como fundamental o investimento na formação do professor numa perspectiva da constituição do professor crítico-reflexivo, tendo a pesquisa como eixo dessa formação aliada à ideia da concepção do trabalho docente de forma colaborativa. 
Conforme Victor (2009), a LDBEN no Art. 59, inciso III, apresenta dois perfis de professores para atuarem com os alunos que apresentam necessidades educacionais especiais: "Professores com especialização adequada em nível médio ou superior, para atendimento especializado, bem como professores do ensino regular capacitados para a integração desses educandos em classes comuns".

Rabelo (2014) defendeu a dissertação "O bebê surdo na Educação Infantil: um olhar sobre inclusão e práticas pedagógicas". Utilizou-se como aporte teórico a perspectiva Historico-Cultural do desenvolvimento humano, "sob a perspectiva que o sujeito se constitui nas relações sociais, como um ser ativo que transforma e é transformado nessas relações" a partir da mediação da linguagem, em especial LIBRAS.

Gonring (2014) "A criança com síndrome de Asperger na educação infantil: um estudo de caso", dissertação desenvolvida a partir da matriz histórico-cultural e estudos da sociologia da infância (SARMENTO; CERISARA, 2004; CORSARO, 2011). Destaca-se, dentre seus objetivos indagar sobre as principais possibilidades e/ou dificuldades encontradas pela unidade de ensino mediante o processo de ensino-aprendizagem da criança com Síndrome de Asperger e, com relação aos resultados, "a necessidade de reconhecer o cotidiano da Educação Infantil como um rico espaço para todas as crianças se desenvolverem e produzirem conhecimentos com seus pares e por meio das mediações pedagógicas dos professores".

Garcia (2007, p. 13) analisou sete documentos que norteiam o trabalho pedagógico relacionado à Educação Especial, sendo dois internacionais (UNESCO) e cinco nacionais (MEC). A autora percebeu alguns conceitos gerais presentes nesses documentos: "qualidade, inclusivo, inovação, não-tradicional, não rígido, não homogêneo, dinamicidade, movimento, atendimento ao local". Para a autora, "tais ideias remetem para a construção de um imaginário que relaciona um currículo flexível a um trabalho pedagógico inclusivo, dinâmico, inovador, que atende ao mesmo tempo à diversidade humana e à identidade cultural local”.

As práticas inclusivas que acompanham esses sujeitos nos primeiros anos de vida necessitam incorporar o cuidado com os sujeitos crianças e oferecer uma educação que ultrapasse as questões clínicas. Eis o desafio de se pensar práticas educativas que reconheçam o devir minoritário das crianças, as parcerias com suas famílias e as conquistas que ultrapassem a restrição do acesso ao 
conhecimento pelas crianças com necessidades educativas especiais.

\section{A experiência de inclusão no CMEl}

As classificações ou rótulos que necessitamos para nomear a deficiência estão presentes desde o primeiro momento que os pais chegam ao CMEI. Já na ficha de matrícula existe a pergunta: Ele possui alguma Necessidade Educativa Especial? Ele tem alguma deficiência? Sem menosprezar a necessidade de nos apropriarmos do conhecimento que tem sido produzido ao longo dos tempos sobre as diferentes síndromes e deficiências que existem, a partir do momento que se identifica e rotula a criança, todas as ações são direcionadas e planejadas a partir das referências que se dispõe sobre o caso. Neste sentido, há uma tendência a buscar mapear as impossibilidades da criança e, sendo assim, direcionar as práticas pedagógicas de acordo com as suas limitações. Contrariando essa lógica, tais conhecimentos podem, também, mobilizar saberes específicos e direcionar o olhar docente para as possibilidades do currículo, a plasticidade do ser humano e mobilizá-lo a fazer o melhor por cada criança; tratar suas diferenças como possibilidades de ampliar a formação humana, construir laços de amizade, tolerância e compreensão.

Algumas crianças com NEE estão no CMEI desde o primeiro ano de vida e são acompanhadas por diferentes professores, outras são matriculadas vindas de outras instituições. Nestes casos, a equipe pedagógica solicita o último relatório da criança. Há, também, crianças que nunca frequentaram a educação infantil e, dentre esses casos, Maria ${ }^{5}$ de 03 anos foi matriculada no Grupo IV (03 anos) do turno vespertino. Para surpresa de todos, a referida criança apresentava várias tipologias de autismo e a mãe não havia percebido ou havia sido orientada a respeito (relato da mãe). Quando a professora, junto à equipe pedagógica, conversou com a família, foi relatado que Maria morava em outro Estado e havia se mudado há pouco tempo para o bairro. Iniciou-se um trabalho de acompanhamento especializado e encaminhamentos foram dados para qualificar a ação da família e da instituição infantil.

A família comunicou, em meados de junho, que estava se mudando e retiraria a criança da instituição. Como a professora já havia conseguido estabelecer várias rotinas e Maria estava envolvida com os colegas, foi solicitado que a mãe mantivesse a frequência ao CMEI sempre que possível, 
tendo em vista a dificuldade do autista em assimilar mudanças. Outra avaliação feita pela professora e equipe pedagógica era que Maria estava se desenvolvendo e já conseguia progressos significativos na fala, controle dos esfíncteres e relacionamento. A família acatou a solicitação e, sempre que possível, Maria estava presente e participando das atividades.

Das crianças que chegam bebês, temos Suely. No Grupo I e II (respectivamente, 2012 e 2013) Suely vivenciou diferentes experiências, interagiu com os colegas e apresentava comportamento adequado à faixa etária, entretanto, a fala era um fator observado por todos: ela não conseguia se comunicar como as demais crianças. Até os colegas, quando estimulados a imitar a Suely, faziam sons inteligíveis. Era uma situação que se esperava passageira, pois cada criança tem o seu tempo e desenvolvem-se de acordo com outros fatores, interações sociais e estímulos; numa relação dialética entre o biológico e o cultural.

Quando se iniciou o ano letivo, a fala ainda não ocorria e Suely já apresentava outras tipologias do autismo. A mãe compartilhou essa inquietação com a professora e equipe pedagógica e começaram as investigações, idas a médicos e, para surpresa de todos, veio o diagnóstico de autismo, uma criança de 03 anos. As práticas pedagógicas ganharam novas dimensões; o tratamento para com Suely também sofreu interferência a partir do diagnóstico. Foi designada uma Assistente de Educação Infantil (pois a faixa etária exigia tal profissional) para acompanhar a criança nos diferentes tempos e espaços da instituição. Isso ocorreu ao longo do ano letivo e, como Suely passou a compor o Público Alvo da Educação Especial, iniciou o trabalho no contra turno, sendo acompanhada pela professora do AEE.

Conforme relato da Professora do AEE, Suely apresentou grande avanço desde o início do atendimento em 08/08/2014. No início, chegava aborrecida tendo reações de agressividade, entretanto, mostrou-se mais sociável através das intervenções. É possível perceber essa formação humana a partir desse fragmento:

Chega alegre, já na descoberta das atividades que serão desenvolvidas. Necessita de diversas atividades durante o atendimento, pois seu tempo de concentração é pequeno. Iniciamos as atividades com um quadro de comunicação, onde retrata os momentos na escola e questões como beber água, banheiro e comer. Suely compreendeu muito bem do que se tratava, apontando e mostrando o que queria fazer. Aos poucos fui controlando o tempo de estar dentro da sala de atendimento, mas em alguns dias necessita estar em outros espaços, dessa forma, vamos para o pátio onde a mesma interage com as crianças do turno matutino. Ressalto que o ponto principal de seu desenvolvimento tem sido a socialização com os colegas, que brincam e socializam brinquedos com a mesma. Grande avanço, já que não gostava de compartilhar. [...] Para explorar a questão identidade, venho buscando através de fotos e seu nome, fazer com que a mesma se reconheça. Em relação à percepção tátil, tem se mostrado mais segura nos momentos em que 
toca algo novo. Necessita primeiro que eu toque, para que depois venha pegar, manusear ou simplesmente tocar. Um sucesso, já que tem aceitado bem novos materiais! Com relação ao desenvolvimento da oralidade tenta expor seu ponto de vista, através de palavras soltas. Seu vocabulário tem aumentado e geralmente repete a última palavras que lhe dizemos. Busca estratégias para vencer as dificuldades, chegando inclusive a buscar alternativas de solicitar ajuda a um colega ou adulto. [...] $\bigcirc$ relacionamento escola/família tem sido de grande importância ao atendimento e também ao desenvolvimento de Suely.

Ao analisar o processo de construção da identidade de Suely, destaca-se o papel da linguagem no processo na consolidação do pensamento infantil, um importantíssimo mecanismo de formação humana apontado por Vygotsky (2007). A afetividade é outro fator preponderante para aproximar Suely e possibilitar a construção de sua autonomia e identidade. Conforme Carvalho (2003), o movimento, a afetividade e a inteligência constituem a tríade que Henri Wallon toma como referência constante para buscar compreender a construção do eu, da personalidade e do homem enquanto ser biológico e social.

Outra criança que compõe essa coletividade chegou transferida. O relatório que o acompanhou não indicava nenhuma alteração de comportamento, não apresentava particularidades sobre a criança. Hélio, uma criança de 04 anos, foi matriculada em meados de 2013. Quando passou a frequentar as aulas, foi possível avaliar que ela apresentava alguns comportamentos e atitudes típicas de autismo. A equipe pedagógica passou a investigar e acompanhar o caso junto à família. Uma característica que marcou 2013 eram as constantes faltas e por períodos longos. Hélio, por não vivenciar uma rotina a longo prazo, apresentava resistência ao tempo dentro de sala e, sempre que vinha, fugia e passa boa parte do tempo pelos corredores. Ao final de 2013 não havia um diagnóstico, apenas uma suspeita. Como resultado da avaliação do grupo de professores que atuaram com Hélio, para 2014 foi solicitado uma professora da educação especial em tempo integral, pois até então, os atendimentos sempre foram parciais: apenas duas vezes por semana existia um trabalho de acompanhamento das crianças com NEE.

Hélio, logo no início do ano letivo, foi recepcionado pela professora do AEE e a família foi convidada a participar diretamente no trabalho junto à instituição. De posse da avaliação do ano anterior e, numa perspectiva de compreender as atitudes de Hélio, iniciou-se um diálogo profícuo entre a professora regente, a professora do AEE e o professor de educação física. Buscavam-se caminhos para um trabalho colaborativo, articulado e integrado. Essa criança passou a mobilizar diferentes saberes desses profissionais e, neste sentido, desenvolveu-se uma prática colaborativa no intuito de aprimorar o trabalho pedagógico e alcançar as particularidades de Hélio, um sujeito 
ímpar, inteligente, criativo e desafiador. Contudo, essa articulação era um desejo e não se efetivou automaticamente. Foram encontros e desencontros ao longo de 2014, fato a ser abordado mais adiante neste artigo.

A referida instituição infantil também atende crianças com surdez. Trata-se de uma unidade referência no atendimento de crianças surdas e suas famílias. Em 2014 o CMEI atendia 04 crianças matriculadas nos Grupos III e VI. Esse trabalho é acompanhado por uma professora bilíngue (ouvinte) e uma professora de Libras (surda), em cada turno. O trabalho com as crianças tem desafiado os profissionais da instituição a se apropriar da Língua Brasileira de Sinais (LIBRAS) e criar mecanismos de comunicação com esses sujeitos. As crianças das turmas que são atendidas também acabam se apropriando da LIBRAS e a convivência entre pares permite minimizar as diferenças. Questiona-se quem está sendo incluído nesse processo, quem é o diferente?

E os cadeirantes? São duas crianças em condições distintas de comprometimento. Isabel está no CMEI desde bebê. Trata-se de uma menina linda, inteligente, faladeira e de bem com a vida; José, uma criança bem comprometida corporalmente, os olhos vivos, um sorriso largo e uma alegria que contagia a todos. Desde bebê foram desafiados a superar seus limites, os limites dos espaços, da cadeira de rodas, das distrofias musculares, das impossibilidades que são apresentadas diariamente pela instituição. Isabel, em 2014, foi transferida para outra instituição infantil, mas retornou após uma experiência negativa relatada pela mãe: ao chegar à nova instituição foram recebidas pela professora de sala que começou a reclamar da possibilidade de ter uma "deficiente" no grupo de alunos e isso gerou um mal estar. A mãe retornou ao CMEI e solicitou sua rematrícula, pois reconheceu quão bem tratada e amada sua filha era pelos profissionais da instituição.

Ela frequentou o Grupo VI, vespertino e mobilizou diferentes saberes, construiu amizades e demonstrou suas capacidades, superações e alegria e viver. Os colegas abraçaram Isabel e demonstraram que a diferença é apenas um detalhe e eles não se importavam, pelo contrário, viveram as possibilidades intensamente. José, por não verbalizar seus desejos, impunha-se pelo choro, "caras e bocas" e demonstrava sua indignação sempre que permanece muito tempo na cadeira. Os colegas, talvez por não saberem como agir, tentavam se comunicar com ele e sempre estavam perto da cadeira de rodas, acariciavam seu rosto, pegavam na sua mão e, quando possível (quando José estava fora da cadeira) adoravam passear na cadeira de rodas. 
Todas essas crianças desafiaram os professores a pensar, planejar, executar, refletir e avaliar suas práticas docentes. O currículo da instituição foi continuamente tensionado para alcançar as diferentes formas de ser humano6, a integrar diferentes sujeitos e proporcionar experiências significativas para todos. As turmas que essas crianças estavam inseridas exigiam práticas compartilhadas, planejamento coletivo e intervenções articuladas a partir dos interesses comuns, mas nem sempre possíveis.

Diante da impossibilidade de abordar as especificidades de todos os sujeitos e suas particularidades/singularidades relatadas neste artigo, passa-se a analisar relatórios dos professores de apenas duas crianças: Hélio e José. Tal escolha se justifica pelo recorte do artigo e a perspectiva investigativa de compreender as possibilidades de uma prática compartilhada, com planejamento coletivo e a busca de parcerias no fazer docente.

\section{Dois meninos incríveis: práticas pedagógicas inclusivas}

Em 2014, com a chegada da nova professora do AEE, área de deficiência intelectual, e sua permanência ao longo da semana, tendo em vista que nos anos anteriores a professora atendia duas vezes por semana, foi possível ampliarmos o diálogo e avaliarmos o Hélio com maior cuidado. Nos primeiros meses havia uma necessidade de convencer a família da importância de manter a frequência do aluno, uma vez que sua assiduidade era inconstante. A rotina na educação infantil, dentre efeitos positivos e negativos, ajuda a organizar o desenvolvimento da criança e permite concretizar um trabalho em longo prazo, além de dar segurança á criança e minimizar possíveis resistências internas.

Os primeiros diálogos dão conta dessa troca de informações e investigar coletivamente as possibilidades de trabalho com Hélio. Apesar das “tipologias de autismo", o aluno apresentava bom diálogo com os adultos e colegas, interagia com a proposta de aula, demonstrava bom relacionamento com os colegas, não apresentava agressividade nas relações pessoais e possuía uma linguagem com bom vocabulário. Após diálogos, entendemos que a melhor forma de alcançar um bom resultado com Hélio era pela via da afetividade. Percebeu-se que o "toque físico" poderia ser a sua

6 Professor José Francisco Chicon, Adjunto do Departamento de Ginástica e do Programa de Pós-Graduação em Educação Física (CEFD/ UFES), durante palestra na UFES, argumentou que o ser humano não é único, mas somos diferentes. Existem diferentes formas de "sermos humanos" (20|4). 
primeira linguagem do amor. De acordo com Gary Chapman (1997), as cinco linguagens de amor são: Palavras de Afirmação; Qualidade de Tempo; Receber Presentes; Formas de Servir; e Toque Físico. Segundo o autor, todas as linguagens estão presentes na vida da pessoa, porém, sempre haverá uma que falará mais forte, a qual denomina "primeira linguagem do amor":

Já se sabe há bastante tempo que no período da primeira infância uma criança desenvolve formas emocionais únicas. Por exemplo, há algumas que possuem um padrão muito baixo de autoestima, ao passo que outras o têm muito elevado. Algumas desenvolvem padrões de insegurança, enquanto outras crescem sentindo-se seguras. Algumas se sentem amadas, queridas e apreciadas, e outras, mal-amadas, incompreendidas e desapreciadas (p. 7). [...] o toque físico é uma forma de se comunicar o amor emocional. Inúmeras pesquisas na área do desenvolvimento infantil chegaram às seguintes conclusões: Os bebês que são tomados nos braços, beijados e abraçados desenvolvem uma vida emocional mais saudável do que os que são deixados durante um longo período de tempo sem contato físico (CHAPMAN, 1997, p. 86).

Em contato com Hélio, era possível perceber em suas falas que existia uma "autoimagem distorcida", com adjetivos pejorativos que se autointitulava: "eu tenho problema", "eu sou doente" ou algo desse gênero. Tudo indicava que havia uma reprodução das falas vivenciadas em outros ambientes.

Diante disso, buscou-se envolver Hélio nas atividades, estimulá-lo a abraçar, demonstrar carinho por ele e tentar uma aproximação física ao longo das atividades. Os estímulos corporais foram oferecidos a todos as crianças da turma e ora Hélio se aproximava e brincava, ora desejava correr e se concentrar em brincar com um colega (em especial o Davi). Sempre convidamos para vivenciar a atividade quando ele se recusava e pedíamos para experimentar. O problema que percebido era que ele não gostava de esperar, pois ficava irritado e choramingando pelos cantos, balançando-se pelos cantos do pátio quando não era atendido prontamente. Seguem-se alguns fragmentos dos relatórios:

Hélio é um aluno interessante e instiga um olhar atento às suas particularidades. Desde o ano passado, quando chegou ao CMEl, percebemos que ele apresentava algumas tipologias (movimentos repetitivos, balançava o corpo para frente e para trás), recusava-se a aceitar algumas rotinas de permanecer em sala e fazer atividades dirigidas, a comunicação às vezes não ocorria, pois fugia do assunto ou não permanecia no local. Havia uma suspeita de "autismo", mas sem diagnóstico médico. Uma professora da educação especial chegou a avaliá-lo e indicou que havia um "problema comportamental" e descartou a possibilidade do autismo (Professor de Educação Física).

Hélio não possui laudo médico, é carismático, simpático e algumas vezes afetuoso. Muito esperto, conhece os amigos pelos nomes, gosta de questionar sobre tudo, demonstrando grande interesse em tudo o que é novo, porém ao início desse semestre foi-se observado que Hélio apresenta algumas dificuldades como: Dificuldade em manter e aceitar as rotinas da sala de aula e escola; Resistência em atender comandos solicitados e regras de jogos; Resistência em respeitar professores e colegas; É agressivo consigo mesmo e com o outro quando contrariado; Nas atividades onde o aluno deve utilizar a comunicação (expressão) às vezes encontra dificuldade, dando respostas inconsistentes ao que lhe foi perguntado; Durante algumas atividades vira a cabeça para o lado ficando totalmente distraído; Possui movimento estereotipado (balança o tronco para frente e para trás); Grita com frequência; Encontra dificuldade em ficar parado por muito tempo; Demonstra ter dificuldade em concentração e atenção. Gosta de correr, pular, dançar. Identifica partes do corpo, mas encontra muita dificuldade no uso das emoções, na revelação das 
tristezas, ansiedades, segurança. No início do semestre, tornou-se evidente que no aspecto sócio-afetivo revelado através das atitudes refletidas na convivência diária e social, que Hélio apresenta mudanças de temperamento que intercalam entre alegria e agressividade. $\bigcirc$ aluno sente a necessidade de ser o centro das atenções há quase todo o instante. Busca apoio quando necessário, sentindo-se orgulhoso do que consegue fazer e feliz quando é elogiado. [...] Nesse início de $2^{\circ}$ semestre podemos dizer que Hélio vem apresentando grandes avanços. Para tanto, Hélio tem apresentado um comportamento bem diferente ao do $1^{\circ}$ semestre. Muito mais afetuoso, aceita receber carinho, atenção e acima de tudo retribui. Hélio já não tem mais dificuldade em manter e aceitar as rotinas da sala de aula e escola, o que tem ajudado muito em seu relacionamento com o outro. [...] Sente-se mais seguro quanto às emoções, revelando-se muito carinhoso e atencioso, preocupando-se com os colegas ou profissionais da escola. A família também tem buscado o acompanhamento médico, tanto que, neste semestre Hélio passou a fazer uso de medicação (Professora da Educação Especial).

O trabalho colaborativo, se assim é possível dizer, partiu da iniciativa da professora do AEE, numa tentativa de dialogar com o projeto de sala e demais atividades dos professores dinamizadores de Arte e Educação Física. Tendo em vista a não necessidade de adaptações nas atividades, trabalhou-se com músicas e dinâmica de grupo visando à interação social; movimentos do corpo e percepção sensorial motora. Estimulava-se sempre para desenvolver a imaginação, criatividade e afetividade, para que a partir dessa alteridade, como propõe Bakhtin (2003), venha estabelecer relações com a sua forma de pensar e o modo de ser do grupo social ao qual pertence.

Utilizou-se de músicas e histórias para despertar na criança o prazer de ouvir e sentir, contribuindo com informações sobre diversas formas culturais de lidar com as emoções e com questões éticas, além de colaborar para uma rica fonte de aprendizagem de novos vocabulários, organizar ideias e pensamentos, aguçar o prazer pela leitura, confrontar a realidade e a fantasia, trabalhar valores presentes em nossa sociedade. Buscou-se promover o acesso, a participação e a aprendizagem de Hélio a partir de ações que se orientassem no desenvolvimento integral, nos aspectos intelectual, emocional, físico e social, complementando a ação da família em seu processo de construção pessoal e de conhecimentos, oportunizando-lhe desafios e vivências, promovendo sua crescente autonomia.

Os relatos da professora regente e da professora de artes resumem bem esse processo:

Diante do que foi exposto o aluno alcançou um bom desenvolvimento, participando ativamente das atividades. Ressaltamos que a partir do trabalho com a produção de textos orais, o aluno ampliou suas possibilidades de articulação do diálogo com os colegas e a professora. Atualmente é capaz de expor seu ponto de vista, e ouvir a opinião dos outros colegas. Levanta hipóteses a respeito dos discursos que ouve, tanto por parte dos colegas como dos adultos. Com relação à produção de textos escritos ainda precisa de avançar no que se refere a coordenação motora fina, para que assim amplie as possibilidades de escrita, no entanto, a falta dessa habilidade não tem sido impedimento para a apropriação do reconhecimento das letras, pois ele tem muito interesse em listá-las. Com relação à educação matemática reconhece os numerais de I a 5 e tenta quantificar outras quantidades fazendo relação números e objetos. Nos aspectos pertinentes as relações interpessoais com os colegas alcançou a habilidade de brincar em grupo. Alimenta-se na escola fazendo suas próprias escolhas na hora da alimentação. Tem necessidade em ter amigos sempre. [...] Conta os acontecimentos de sua casa, fazendo sempre a relação (Professora Regente de sala). 
aluno Hélio é uma criança participativa, amorosa e prestativa. Se adapta bem às atividades propostas sem nunca precisar ter que desenvolver atividades paralelas direcionadas a ele nas aulas de Artes. Consegue utilizar os materiais sem apresentar problemas, agonias ou gasturas. É um aluno concentrado, mas seu tempo de atenção é mais curto se comparado à maioria dos alunos de sua turma. Apresentou uma melhora de comportamento considerável, pois no início do ano não se mantinha em sala por uma aula inteira e hoje já permanece. Seu diálogo também evoluiu, conseguimos hoje sentar e conversar com Hélio e ter um retorno, situação que dificilmente era alcançada no início do ano letivo. Acredito que essa melhora seja fruto de um trabalho da escola em parceria com a família, que renderam bons resultados e se contínuo, dará abertura a novas conquistas (Professora de Artes).

A análise das práticas educativas do CMEI com relação a Hélio indicam conquistas, principalmente nas questões relacionais. Conforme os relatos, Hélio tem apresentou um bom desenvolvimento ao longo do ano. Foi mais assíduo e muito mais tranquilo, apresenta estar mais feliz. Está escrevendo seu nome com mais segurança, já é capaz de contar até 10 utilizando os dedos das mãos em alguns momentos. Sua oralidade está muito mais clara, pois conseguimos entender o que diz. Apresenta grande avanço na coordenação motora fina, tem mais firmeza na mão na hora de recortar e seu traçado mais firme. Tem se relacionado muito bem com os colegas de sala. Respeita os professores, colegas e profissionais da escola. Às vezes, sente necessidade de sair da sala e dar uma voltinha (pede para beber água, ir ao banheiro mais que o normal), mas isso se resume em muito menos comparado ao início do ano. Há alguns dias em que chega cansado, então, senta isolado e fica se balançando para frente e trás, mas depois logo vem e começa a se relacionar com os colegas. É incrível como agora se preocupa com os menores, tem carinho e quer cuidar. Com maior autonomia, sente-se mais seguro na hora de realizar qualquer atividade. Tudo isso se deu, através de muita atenção e carinho por parte de todo corpo docente e colegas de turma. Quanto aos aspectos motores, percebemos que apresenta alguma dificuldade de coordenação motora grossa, pouca concentração, dificuldade de equilíbrio. Todavia, não interfere diretamente nas possibilidades de interação com as propostas de trabalho desenvolvidas.

Nas aulas de educação física, Hélio não apresentou dificuldades de se envolver com a turma. As atividades foram marcadas por brincadeiras de cordas, bola, dança, pneus, balanços, slackline, "trepa-trepa" e atividades livres. Hélio possui uma oralidade bem desenvolvida, com um rico vocabulário e consegue se expressar com facilidade. Nas brincadeiras ele se envolvida a partir do seu interesse e conseguia uma boa interação com a turma, porém, a atenção dele parece-nos um pouco curta e não demonstra paciência em esperar sua vez. No "trepa-trepa", Hélio conseguir subir e fazer movimentos de sustentação e queda. Sua coordenação motora está de acordo com a faixa etária, 
apenas o movimento de marcha apresenta certo estereótipo cambaleante. No futebol, ele consegue interagir com alguns colegas, mas demonstra pouca paciência em dividir a bola. Todavia, consegue estar em grupo e, apesar das reclamações, brincam efetivamente de futebol.

$\mathrm{Na}$ bola de pilates ele conseguiu fazer os movimentos junto com os colegas de rolar, deitarse de costa e brincar de ginástica com a turma. Pular corda e cobrinha também houve sua participação. Na atividade com artes (vivência a partir do artista plástico Kandinsky), Hélio não se sentiu confortável. Ficou o tempo todo recluso na "casinha" do pátio e ficou inquieto com o som do Rock. Parecia bastante perturbado e seu movimento de balanceio corporal ficou mais rápido e acentuado. Não foi possível movê-lo para fora e que participasse da atividade.

Outra atividade que demonstrou interesse foi o boxe. Hélio evidenciou o desejo participar da atividade com o saco de pancadas e brincou interagindo com os colegas. Dividir o brinquedo ainda é um problema para ele, mas, apesar das reclamações que faz, consegue brincar e usufruir da atividade. A subida na corda foi outra atividade que conseguiu se envolver com as crianças. Hélio, ao observar o movimento, entrou na fila e quis subir (escalar verticalmente a corda, com suporte do professor) e tocar o sino que foi colocado propositalmente no topo. Ele fez esse movimento com alegria e interesse, demonstrando confiança e destreza corporal tanto na subida, quanto na descida. Hélio mantém a estereotipia do espectro autista, mas carece de maior observação e acompanhamento pedagógico. O trabalho com a família precisa ser acentuado para minimizar "erros" no trabalho com essa criança e estimular seu desenvolvimento, criatividade e autonomia.

José é uma criança especial, não no sentido da educação inclusiva, mas nas possibilidades que ele demonstra de se relacionar com as pessoas. Seu olhar e o sorriso são as marcas que traz consigo, formas que utiliza para se comunicar, expressar sentimentos de alegria, dor, tristeza, incômodos quando necessita de trocar fraldas ou qualquer outra situação. Se expressa corporalmente quando está gostando da atividade e, também, sabe demonstrar quando não deseja tal experiência. Exige muito do profissional que o acompanha, tendo em vista a necessidade da atenção contínua, sua dependência para se locomover, se alimentar, higienização e troca de roupas. É um aluno cadeirante, com deficiências múltiplas, mas isso já está posto. O que nos interessa neste relato são suas capacidades e, destaco mais uma vez, seu sorriso é nosso referencial quando estamos com ele.

Conforme laudo clínico, José apresenta paralisia cerebral (CID10-G 80.0) caracterizando 
tetraplegia espástica e grave atraso neuropsicomotor e (CID10-F71) retardo mental moderado. A escola vem mantendo um diálogo com a família na tentativa de ajudar o aluno a se aproximar do currículo ministrado em sala. A família é presente e busca todos os recursos possíveis para ajudar o mesmo. José é carismático, encontra-se em desenvolvimento de sua oralidade, às vezes tenta balbuciar algumas palavras. Vem apresentando um desenvolvimento significativo de aprendizagem participando na maior parte das vezes das mesmas atividades aplicadas na turma.

Nesse processo de aprendizagem, realizou-se contato com a APAE que o atende em alguns dias da semana, buscou-se um laudo médico e quais atividades eles estavam fazendo com José. Os professores se ofereceram a ir até o local e observar seu desenvolvimento. Essa parceria não foi possível, tendo em vista a Prefeitura de Vitória não possuir vínculo com a instituição. Contudo, eles encaminharam um parecer indicando quais atividades eram recomendas e quais cuidados era preciso ter com ele, em especial o pescoço e o apoio sobre a coluna.

As intervenções caminharam sob essa ótica e José, conforme consta nos registros, foi estimulado para facilitar o processo de inclusão e adquirir independência em suas relações com o mundo. José foi assíduo e demonstrou muito prazer em estar no ambiente escolar. Responde a estímulos sonoros, sempre que é chamado pelo; busca com o olhar e demonstra alegria corporalmente (balança as pernas e a cabeça); conhece a voz dos adultos que estão em contato contínuo no CMEI: as cozinheiras, a estagiária, a pedagoga, os professores. As atividades desenvolvidas com a turma são oportunizadas a todos, mas existem momentos para uma interação individual com José.

No início, apresentava grande dificuldade em movimentos como de preensão de objetos, contudo tem mostrado grandes avanços, ainda apresenta ter medo de tudo que é novo, principalmente nas aulas de Educação Física. Todavia, é sempre incluído nas atividades, chora na primeira tentativa, mas da segunda em diante já vai perdendo um pouquinho do medo. José tem grande interesse no aprendizado. No início do ano, por haver trabalhado com atividades tradicionais (brincadeiras individuais e coletivas), acompanha a turma e interagia tangencialmente. Sempre era acompanhado pela estagiária e pela professora do AEE. Foi possível desenvolver com ele atividades paralelas, que às vezes, as crianças da turma desejavam participar.

$\mathrm{Na}$ tentativa de analisar as práticas pedagógicas que envolveram José e contribuíram para sua formação humana, buscar-se-á descrever alguns fragmentos dos relatórios dos professores que 
o acompanharam ao longo de 2014:

A partir do projeto "Identidade" e "Viajantes Estrangeiros no Espírito Santo" da professora regente, bem como das atividades dos professores dinamizadores de Arte e Educação Física, caminhamos por um viés onde foram desenvolvidas várias atividades no coletivo e individual, adaptado para favorecer o processo de ensino aprendizagem de José. Trabalhamos com: músicas e dinâmica de grupo visando à interação social, movimentos do corpo e percepção sensorial. Pintura, colagem, massinha para o desenvolvimento motor. Filmes, vídeos, teatro. Desta forma, possibilitando o desenvolvimento da esfera cognitiva tanto de José, bem como todos os demais alunos da turma. Em geral, as atividades adaptadas são desenvolvidas com toda turma exigindo estratégias por parte dos professores, modos diversificados de exposição nas aulas, relacionando os conteúdos curriculares a situações do cotidiano mostrando exemplos concretos para ilustrar ideias mais complexas, contribuindo assim para um efetivo desenvolvimento da aprendizagem. Através da leitura de histórias, proporcionamos momentos em que José pode conhecer a forma de viver, pensar, agir, o universo de valores, costumes e comportamentos de outras culturas situadas em outros tempos e lugares que não é o seu, para a partir daí poder estabelecer relações com a sua forma de pensar e o modo de ser do grupo social ao qual pertence. Durante o desenvolvimento das atividades, podemos notar que José mostra interesse e entusiasmo através de expressões faciais, corporais e balbucios. Utilizando músicas para despertar em José o prazer de ouvir e sentir, confrontando a realidade e a fantasia, trabalhando valores presentes em nossa sociedade. As atividades do aluno são acompanhadas pela professora do AEE, que realiza o trabalho articulado/colaborativo na escola. [...] Os planejamentos são pensados de forma que haja atividades direcionadas alcançando suas limitações. [...]. Apesar de José balbuciar algumas palavras e tentar falar outras, foi proposto iniciarmos a tentativa de utilizar recursos da CA (Comunicação alternativa). Iniciamos as tentativas para que segure diversas coisas, como a colher adaptada na hora do almoço, as frutas no lanche e o copinho com asa. Sentar na mesma cadeira que os outros colegas com suporte da professora para desenvolver as atividades de sala. A professora também tem adaptado atividades para que José possa alcançar o currículo proposto (Professora do AEE).

Durante as atividades desenvolvidas, pode-se notar que José apresentou grande avanço, pois conseguiu segurar sem adaptação por um tempo maior o pincel, lápis ou giz de cera. Diverte-se muito ouvindo músicas e gosta de dançar. Gosta também de participar das atividades, cantar e ouvir histórias. Relaciona-se na comunidade escolar, é carinhoso e divertido. Demonstra interesse nas atividades que lhe são propostas. Gosta de jogos e brincadeiras, já demonstrando prazer em participar nas aulas de educação física e artes. Nas aulas de Arte, contribui da melhor maneira possível realizando as mesmas atividades que os colegas. Como é incrível vê-lo abrir a mãozinha e manter o braço estendido para que a professora possa fazer bolinhas de massinha em sua mão! O importante é sempre orientá-lo previamente sobre as tarefas que serão realizadas no decorrer das aulas e haver a mediação de um adulto na execução e desenvolvimento das atividades.

Gosta de brincar no coletivo, sentar no meio dos brinquedos de encaixe, brincar de boneca com as meninas, jogar bola com os meninos. Consegue identificar quando está com a fralda suja ou com fome e se esforça na tentativa de avisar, onde costuma chorar ou rir sem parar. Alimenta-se bem, necessitando de auxílio para isso. A participação da família, inclusive nos passeios e a socialização com os colegas da turma contribuem infinitamente para seu desenvolvimento. A escola prima por promover o acesso, a participação e a aprendizagem de José a partir de ações que se orientem 
no desenvolvimento integral, nos aspectos intelectual, emocional, físico e social, complementando a ação da família em seu processo de construção pessoal e de conhecimentos, oportunizando-lhe desafios e vivências, visando sua crescente autonomia.

Ao analisar os relatos da professora regente e, também, de artes, percebe-se o desejo de reconhecer as qualidades e potencialidades de José. Essa postura corrobora com o conceito de escola inclusiva, na qual todos têm direito à educação e as diferenças contribuem para qualificar o processo de aprendizagem:

[...] desenvolvemos um projeto intitulado "Viajantes Estrangeiros no Espírito Santo". Trata-se de um trabalho constituído por pesquisas relacionadas aos sujeitos que vieram a nossa Província/Estado do Espírito Santo, ora para visitar, ora para trabalhar (desbravar invadindo, ou serem explorados). Fazem parte desses viajantes os negros (escravos), os brancos (orientais e ocidentais) incluindo-se entre eles os príncipes e donatários e até mesmo crianças que vieram com a missão de povoar o espaço e também "colonizar". [...] o aluno alcançou bons desenvolvimentos no que se refere aos movimentos do corpo, pois diante das dinâmicas utilizadas, durante as atividades foi levado a participar de uma forma ativa. Atualmente movimenta o corpo fazendo tentativas e conseguindo pegar alguns objetos. Podemos observar que ele entende e responde aos estímulos e as explicações dadas, principalmente se estas explicações forem explanadas de forma lúdica. Gosta muito de ouvir histórias e expressa seu entendimento a partir do sorriso e do olhar. Faz tentativas de pegar os livros. Tem prazer em desenvolver atividades com tinta e massinha de modelar. [...] Dançar é uma de suas atividades prediletas. Seu movimento desenvolveu-se de tal forma que tenta sair de sua cadeira. [...] Tem tentativas espontâneas de se comunicar oralmente. Interage durante os passeios da escola. [...] Quando está insatisfeito demonstra com o olhar e com o choro (Professora Regente de sala).

José, ao longo do $1^{\circ}$ semestre, apresentou um avanço significativo em relação às atividades propostas em sala e adaptadas a ele. Alguns materiais como a massinha, ele sente certa agonia, criando uma resistência, mas os outros materiais como o EVA, a cartolina, o TNT que têm textura ele passou a aceitar e assim participou de todas atividades que na sua maioria são coletivas. A professora do AEE fez uso de vários materiais para ajudá-lo na participação e manuseio, como tesoura, mesa, tudo adaptado para a realidade de José e sempre o inserindo no contexto da aula. Sendo assim, temos uma criança alegre, que demonstra satisfação na aula e sempre amparada por professores e colegas de sala, todos com muito carinho e respeito por ele (Professora de Artes).

No tocante às aulas de Educação Física, houve significativo avanço, uma vez que tem chorado menos nas tentativas de novas atividades, aparentando estar contente com as atividades realizadas. Realiza tudo o que é proposto sem chorar. Gosta quando o tiram da cadeira para caminhar ou jogar bola. A participação da estagiária é fundamental, pois é sustentado por ela e a professora do AEE. José sorri muito e é possível sentir sua satisfação.

Das atividades que foram realizadas, é possível destacar algumas, pois foram significativas para todos os sujeitos envolvidos no processo. Desde José até as cozinheiras. Em especial, destacase a disponibilidade dos professores de Educação Física e do AEE em conversar e planejar práticas que fossem significativas para José. Demonstra-se o desejo colaborativo e a expectativa de bons encontros. Tendo em vista a necessidade ergonômica de atuar com José, alternavam-se as duplas que 
atuavam diretamente com ele nas práticas corporais. Conforme relato do professor:

Balanço - conseguimos que a professora ou a estagiária sentassem e balançasse com ele. De início, ele resistiu bastante (como de costume, pois tudo que é novo o assusta e mexe com sua estabilidade), mas insistimos e ao longo da atividade demonstrou prazer e alegria com um belo sorriso. Quando terminamos essa atividade e colocávamos ora no colchão, ora na sua cadeira de rodas ele "soltava um sorriso de alívio" e brincávamos com ele, uma interação muito prazerosa e gostosa para nós adultos e, pela nossa leitura corporal, também para ele.

Carrinho de mão - este artefato, um carrinho de mão de obra, foi adquirido pela escola quando eu e a professora do AEE estávamos planejando ações conjuntas e atividades que fossem possíveis para envolver José. Foi uma alegria para a turma e uma interação só. Após deixar que observasse os colegas brincando, sendo carregados por mim, colocamos uma "calça jeans com enchimento" e ajeitamos José no carrinho. A primeira experiência foi aterrorizante, ele demonstrou desespero e, se pudesse, sairia correndo. Acalmamos e buscamos alternativa: colocamos a professora do AEE no carrinho e José no meio de suas pernas. Carregamos os dois pelo pátio e, ao longo da experiência, percebemos que foi se acalmando e aceitando a atividade. $\bigcirc$ que ele mais gostou foi quando retiramo-lo do carrinho e colocamos na cadeira.

Pula-pula (cama elástica) - essa foi uma das atividades mais desafiadoras, pois precisávamos que ele tentasse ficar firme com a cabeça e coluna. A professora do AEE entrou com ele e tentávamos pular e fazê-lo pular. Reclamou, como sempre. Depois, deitamo-lo na cama elástica e pedimos que as crianças pulassem calmamente e ele fosse sentido o movimento. Após interações com os colegas, peguei-o no colo, abracei e acomodei-o no meu corpo e comecei a pular com ele. Nesse momento, senti que relaxou nos meus braços e curtiu aquele momento. Foi uma alegria perceber que alcancei meu aluno e possibilitei uma experiência significativa para ele. $\bigcirc$ sorriso é sempre nossa referência.

José surpreende continuamente e é sempre um desafio envolvê-lo nas atividades. Resiste ao novo e, ao observar os colegas, consegue assimilar a tarefa, envolve-se. As crianças são amáveis com ele e, sempre que é retirado da cadeira e colocado no colchão, os colegas pedem para "andar" na cadeira. Esse movimento é aceito e estimula esse envolvimento da turma. O colchão no pátio passou a ser um local de interação entre José e os colegas.

Também foi ofertado um trabalho na bola de pilates. A professora do AEE e a estagiária que o acompanha, iniciaram um trabalho de estimulação e contato com a bola de pilates com $85 \mathrm{~cm}$. Houve interação e indicaram-se diferentes movimentos de frente e costa, pernas e braço. José demonstrou ter gostado da experiência e aceitou muito bem a atividade. O sorriso esteve presente e expressou corporalmente a alegria de participar da aula. Em anos anteriores José demonstrava resistência, mas desta vez apresentou alegria nos movimentos que foram desenvolvidos com ele: deitar-se sobre a bola, rolar, "virar cambalhota", ficar de ponta cabeça e deitar-se de costa sobre a bola foram oportunidades oferecidas. Sua interação foi surpreendente, uma vez que balbuciava alguns sons tentando se comunicar; ria da "conversa" com ele, tentava fazer alguns movimentos autônomos como caminhar apoiado na bola e as crianças da turma interagiram com ele.

Ele ficou várias vezes na cadeira a observar as crianças brincando. O interessante disso tudo 
é a atitude dele: acompanhava com o olhar tudo o que se passava à sua volta; reclamava à sua maneira e constantemente "pedia" para sair da cadeira de rodas; não aceitava essa condição de excluído, tendo em vista demonstrar o desejo de participar com seus colegas de tudo que acontecia a seu redor. Seu olhar continua sendo a melhor forma de comunicação: mexia-se na cadeira para chamar a atenção e quando percebia que conseguia o nosso olhar, tentava "falar" e fazia expressões diversas, como a dizer: “- E eu, quando vou participar?”.

Outra atividade que foi marcante para todos corresponde à atividade interdisciplinar que conseguimos realizar no CMEI: a partir do artista plástico Kandinsky (A criação trabalhos abstratos a partir da música), foi possível desenvolver atividades de arte-movimento. José conseguiu usufruir a partir do empenho da professora do AEE e da estagiária. Foram três períodos intercalados: $1^{\mathrm{o}}$ momento - atirar bolas de soprar cheias de tintas (água + guache) na parede revestida com três metros de tecido "algodão cru". Foi uma verdadeira bagunça e José participou efetivamente, ficando sujo de tinta assim como seus colegas de turma; $2^{\circ}$ momento - utilizar as mãos para pintar outra parede revestida com três metros de tecido. Nessa experiência, as tintas foram dispostas em tampas plásticas e as crianças colocavam as mãos e, ao som de um Rock, interferiam livremente. José, sob os cuidados da professora do AEE e Estagiária, ficou no cantinho e utilizou um pincel para deixar sua marca, além de utilizar as mãos.

O interessante foi perceber seu olhar atento a tudo, concentrado na atividade e sentado no colo da professora a intervir na "tela"; o $3^{\circ}$ momento - utilizar os pés para pintar outro tecido, desta vez estendido no chão do pátio de grama. Da mesma fora, deixamos as bandeiras no chão e as crianças interferiram ao som de música (Tema do filme Missão impossível). José conseguiu deixar suas marcas na obra de arte; o último momento foi o banho - todos estavam sujos de tinta, as crianças ficaram irreconhecíveis, mas com uma alegria no rosto que expressava a felicidade da bagunça vivenciada na escola. José também estava sujo e o "banho coletivo" foi outro momento alegre propiciado às crianças do CMEI.

Avaliamos que sua cognição "está preservada" e consegue compreender o que passa à sua volta. Suas capacidades vão além das condições limitantes que o meio insiste em recomendar. Foi possível, ainda, envolver José com a turma na brincadeira de pular corda, a partir do curta "Cordas"7: a professora do AEE colocava a corda em sua mão e fazíamos o movimento de girar. Ele 
acompanhava tudo com o olhar e ria demonstrando prazer na atividade. A interação com a turma foi fantástica, a ponto de pedirmos às crianças para tomar cuidado, pois ele realmente segurava a corda. "Cobrinha" foi outra brincadeira que ele conseguiu participar "movimentando" a corda com ajuda da professora do AEE.

\section{Considerações finais}

A prática colaborativa e o planejamento integrado dos professores é um desejo, contudo, acontece pontualmente. Há necessidade de organizar momentos dentro da rotina para contemplar as possibilidades de articular o trabalho entre os diferentes professores do CMEI. A educação infantil, à luz da legislação reguladora, orienta que a prática pedagógica seja integrada e evite-se a fragmentação do currículo, uma vez que o sujeito criança é considerado completo e exige uma formação integral, pautado nos princípios políticos, éticos e estéticos.

Os professores de Artes e Educação Física e a professora do AEE, responsável pelo atendimento ao público alvo da Educação Especial, cada vez mais específico/particularizado, nos dizeres de Victor (2012, p 88), “uma professora especialista em educação especial” conseguiram, nas brechas curriculares, articular minimamente suas práticas docentes. As especificidades da Educação Infantil exigem outra perspectiva de atuação, tendo em vista que as crianças são educadas e formadas por todos os profissionais da instituição. Não é possível conceber uma prática educativa, quer seja regular ou inclusiva, distante da integralidade curricular.

Será que a inclusão que buscamos fazer aconteceu para os nossos sujeitos? Queremos crer que sim, pois a cada sorriso alcançado, a cada olhar de alegria, a cada gesto de liberdade, a cada momento de euforia, a cada conquista de movimentos outrora impossíveis, em cada pequeno detalhe de autonomia, de aprendizagem, de acesso às culturas e em todos os momentos que vimos as crianças interagindo entre elas, dizendo "tô nem aî" para o diferente, abraçando a oportunidade de brincar e se divertir, percebemos o nosso trabalho acontecendo. Há sim uma inclusão possível. É a melhor? Talvez não, mas é a inclusão que está sendo possível (com todos os gerúndios da nossa gramática).

A participação das crianças é motivada pelo envolvimento das Assistentes de Educação Infantil, Estagiárias e professores que, ao perceberem possibilidades do trabalho colaborativo, en- 
volvem-se com as crianças, tornam-se crianças e brincam. As crianças devem ser nossa referência de trabalho, tendo em vista estarmos na educação infantil para oferecer práticas de qualidade, formação humana e proporcionar tempos de aprendizagem e estimulação de suas capacidades. Precisamos olhar e refletirmos filosoficamente: o que pode uma criança?

Parece-nos que fizemos tão pouco diante das capacidades desses alunos fantásticos. Aprendemos que o olhar diz muito e o sorriso é uma potente ferramenta a favor da inclusão. Basta que estejamos dispostos a olhar para o outro e percebermos suas capacidades, suas potências. As dificuldades não precisam ser ressaltadas, uma vez que ficam estampadas a quem passa. Mas, aos que param e prestam atenção, percebem que há muito que fazer pelos “Josés," para além, com "os Josés”, crianças que aprendem e ensinam a todos nós o valor da vida e a alegria de viver um dia de cada vez. As possibilidades de aprendizagem ainda são um desafio a pensarmos, bem como o desenvolvimento de outras linguagens que possibilitem às crianças se expressarem com autonomia.

Salles e Farias (2012, p. 58) discutiram o tema “o currículo na educação infantil” e apresentaram consistentes conceitos que colaboram com o presente artigo. Segundo as autoras, "o corpo é, para a criança, objeto de conhecimento e instrumento de exploração e apropriação do mundo". Ao abordar o sorriso do bebê, alegam que o sorriso "é revelador do desenvolvimento do afeto e se constitui como uma resposta a outro ser humano, trazendo a ideia de satisfação, contentamento".

A oferta da educação física no currículo da educação infantil, conforme análise dos relatórios, demonstra qualificar o tempo e as experiências corporais das crianças. Ampliam-se as possibilidades de trabalho colaborativo e reconhece o direito de se movimentar e ter acesso aos saberes e práticas culturais sistematizados na história humana. O movimento pode ser identificado como uma linguagem, todavia, não se limita a essa definição. É possível considerá-lo, também, como conhecimento da cultura corporal, manifestação da expressividade e criatividade, além de configurar modos de ser e estar em sociedade.

\section{Referências bibliográficas}

BAKHTIN, Mikhail. Estética da criação verbal. São Paulo: Martins Fontes, 2003.

BRANDÃO, José R. O que é educação. São Paulo: Brasiliense, 2013.

BRASIL. Ministério da Educação. Secretaria de Educação Especial. Política Nacional de Educação Especial na Perspectiva da Educação Inclusiva. Brasília: MEC, 2008. 
CARVALHO, Elda M. R. Tendências da Educação Psicomotora Sob o Enfoque Walloniano. Revista Psicologia Ciência e Profissão [online], vol.23, n.3, pp. 84-89, 2003.

CHAPMAN, Gary. As cinco linguagens do amor. São Paulo: Mundo Cristão, 1997.

CORSARO, William A. Sociologia da infância. Porto Alegre: Artmed, 2011.

DEBORTOLI, José Alfredo O. Educação física/educação do corpo/educação dos sentidos: novos-velhos e outros discursos na Educação Infantil. In: ANDRADE FILHO, Nelson Figueiredo de; SCHNEIDER, Omar (Orgs.). Educação física para a Educação Infantil: conhecimento e especificidade. São Cristóvão: Editora UFS, 2008.

GARCIA, Rosalba M. C. O conceito de flexibilidade curricular nas políticas públicas de inclusão educacional. (in) JESUS, Denise M. et al (Org.) Inclusão, práticas pedagógicas e trajetórias de pesquisa. Porto Alegre: Mediação/PMV/CDV/FACITEC, 2007.

GONRING, V. M. A criança com Síndrome de Asperger na educação Infantil: um estudo de caso. 2014. Dissertação (Mestrado em Educação). Programa de Pós-graduação em Educação, Universidade Federal do Espírito Santo, Vitória, 2014.

KOHAN, Walter. O. Infância, estrangeiridade e ignorância: ensaios de filosofia e educação. Belo Horizonte: Autêntica, 2007.

NÓVOA, Antônio. O Professor Pesquisador e Reflexivo. Entrevista concedida em 13 de setembro de 2001. Disponível em: http://cursoproinfo100h.blogspot.com/2009/03/o-professor-pesquisador-e-reflexivo.html. Acesso em: 10/12/2010.

QUINTEIRO, Jucirema. Sobre a emergência de uma sociologia da Infância: contribuições para o debate. Revista Perspectiva. Florianópolis, v.20, n.Especial, p. 137-162, jul./dez. 2002.

QVORTRUP, Jens. A infância enquanto categoria estrutural. Revista Educação e Pesquisa, São Paulo, v. 36, n.2, p. 631-643, maio/ago. 2010.

RABELO, Dayane Bollis. O bebê surdo na educação infantil: um olhar sobre inclusão e práticas pedagógicas. Dissertação (Mestrado em Educação). Programa de Pós-Graduação em Educação, Universidade Federal do Espírito Santo, Vitória, 2014.

SALLES, Fátima; FARIA, Vitória. Currículo na educação infantil: diálogo com os demais elementos da Proposta Pedagógica. São Paulo: Ática, 2012.

SARMENTO, Manoel J.; CERISARA, Ana B. Crianças e miúdos: perspectivas sociopedagógicas da infância e educação. Porto: Asa, 2004.

VEIGA, Cynthia Greive. História da educação. São Paulo: Ática, 2007.

VICTOR, Sônia L. As produções acadêmicas em educação especial na Educação Infantil: análise da formação de professores. Revista de Ciências Humanas (Frederico Westphalen. Impresso), v. 13, p. 79-97, 2012.

VICTOR, Sônia L. Sobre inclusão, formação de professores e alunos com necessidades educacionais especiais no contexto da Educação Infantil. In: XXIV Simpósio Brasileiro e III Congresso Interamericano de Política e Administração da Educação, 2009, Vitória. Cadernos ANPAE. Vitória: PPGE/UFES, 2009. p. 1-17.

VIGOTSKI, Lev S. A formação social da mente: o desenvolvimento dos processos psicológicos superiores; organizadores Michael Cole... [et al.]. 7. ed. São Paulo: Martins Fontes, 2007. 
WALLON, Henri. A evolução psicológica da criança. São Paulo: Martins Fontes, 2010. 